\title{
A MODALIZAÇÃO NO PROCESSO DE GRAMATIZAÇÃO NO BRASIL
}

\section{MODALIZATION IN THE GRAMMARIZATION PROCESS IN BRAZIL}

\author{
Sergio Casimiro ${ }^{1}$ \\ Universidade Estadual de Campinas (UNICAMP)
}

\begin{abstract}
RESUMO: Neste trabalho, pretende-se localizar os estudos sobre Modalidade e Modalização no interior dos estudos da História das Ideias Linguísticas. A partir do conceito de Gramatização (cf. Auroux, 1992), que se preocupa com o saber sobre língua e suas tecnologias (dicionários e gramáticas), foi feito um levantamento dos estudos sobre Modalidade e Modalização desde a tradição gramatical grega até se chegar às gramáticas brasileiras. Observa-se a importância de gramáticas produzidas por linguistas como Maria Helena de Moura Neves (Gramática de usos do Português), Mário Perini (Gramática do Português Brasileiro) e Ataliba Castilho (Nova Gramática do Português Brasileiro) na preocupação com o tema "modalidade" sob um viés científico, abordando aspectos como marcas de subjetividade, ou das atitudes dos falantes, no enunciado.
\end{abstract}

PALAVRAS CHAVE: História das Ideias Linguísticas, Modalização, Gramáticas brasileiras

ABSTRACT: In this work, we intend to find studies on Mood and Modality within the studies of the History of Linguistic Ideas. From the concept of Grammatization (cf. Auroux, 1992), which is concerned with knowledge about language and its technologies (dictionaries and grammars), a survey of studies on mode and modalization from Greek grammatical tradition was made to get the Brazilian grammars. We note the importance of grammars produced by linguists as Maria Helena de Moura Neves (Grammar of Portuguese uses), Mario Perini (Brazilian Portuguese Grammar) and Ataliba Castilho (New Brazilian Portuguese Grammar) in concern with the theme "Mood" from a scientific bias, addressing aspects such as brands subjectivity, or the attitudes of the speakers, in the statement.

KEYWORDS: History of Linguistic Ideas, Modalization, Brazilian Grammars

\section{INTRODUÇÃO}

As preocupações com as línguas e a linguagem humana estiveram, e ainda estão, presentes nas mais diversas civilizações, porém de modo diferente

\footnotetext{
${ }^{1}$ Integra ainda o "Centro de Pesquisa Margens", coordenado pela Profa. Dra. Anna Christina Bentes (UNICAMP).Tem experiência nas áreas de Linguística, com ênfase em Análise Linguística, e de ensino de Língua Portuguesa, atuando principalmente nos seguintes temas: Modalidade/Modalização, Referenciação e Categorização, Gêneros Discursivos e Estilo Sociolinguístico.
} 


\section{Revista InterteXto / ISSN: 1981-0601}

\section{v. 10, n. 2 (2017)}

em cada uma delas. Há sociedades em que o conhecimento produzido sobre a língua não passou de simples questões de cunho especulativo e prático, enquanto outras conseguiram desenvolver todo um conhecimento abstrato sobre linguagem e aprimorá-lo através de diferentes aparatos tecnológicos A escrita foi um dos primeiros passos para que se desenvolvessem algumas dessas novas técnicas. Dentre as principais tecnologias desenvolvidas no âmbito de estudos da linguagem estão os dicionários e as gramáticas, dentre os mais antigos e mais utilizados, e, atualmente, o computador passou a desempenhar papel importante com a informatização dessas tecnologias mais antigas.

Sabe-se também que os estudos sobre modo e modalidade não são recentes, sendo os pensadores gregos os primeiros a se preocuparem com isso, já na Antiguidade. No entanto, essa preocupação com a modalidade atravessou o tempo, foi retomada pela lógica e pela linguística contemporânea, e chegou até algumas das gramáticas brasileiras atuais.

Em se tratando de História das Ideias Linguísticas e de se fazer história das ideias linguísticas, o que se propõe é esboçar, nesse novo campo disciplinar, um percurso do estudo da modalidade no interior do processo de gramatização brasileiro, perpassando os primeiros estudos deste tema gramatical na Antiguidade Clássica até se chegar às gramáticas no Brasil. Porém, deve ficar claro que, neste trabalho, o que se tenta fazer não é esgotar o estudo da modalidade num levantamento de todas as gramáticas brasileiras, mas o de apontar em algumas gramáticas nacionais como aparece delineada a questão da modalidade.

Motivado por essa preocupação de se fazer História das Ideias Linguísticas, este trabalho será guiado por algumas questões, que tentarão ser respondidas na medida em que se busca entender a origem e transmissão desse saber linguístico. Tendo por base os objetivos essenciais dessa disciplina, neste trabalho pretende-se verificar em algumas gramáticas brasileiras como a questão da modalização aparece, e refletir, a partir de então, quais fatores são levados em conta para que tal tipo de saber linguístico se 


\section{Revista InterteXto / ISSN: 1981-0601}

\section{v. 10, n. 2 (2017)}

manifeste ou não nesses instrumentos tecnológicos, sem perder de vista a relação Língua/Nação/Estado.

\section{HISTÓRIA DAS IDEIAS LINGUÍSTICAS E MODALIDADE:}

Como aponta Orlandi (2001), a disciplina "História das Ideias Linguísticas" é bem recente, tendo aparecido, no Brasil, com um acordo entre um grupo de pesquisadores brasileiros, liderados por Eni Orlandi e um grupo de pesquisadores franceses, representados, hoje, dentre outros, pelo prof. Dr. Sylvain Auroux. Conforme a mesma autora, esse tipo de pesquisa visa compreender o funcionamento dos instrumentos linguísticos na relação do sujeito com a sociedade na história, aliando, de um lado, Gramática e Dicionário, História da Sociedade e Ideologia e, de outro, Saber Linguístico e Língua Nacional. Trata-se, segundo ela, da constituição do saber e da língua, na instituição. Dessa forma, visa-se conhecer a língua e o saber que se constrói sobre ela ao mesmo tempo em que se pensa a formação da sociedade e dos sujeitos que nela existem.

Nesse sentido, deve ficar claro que fazer "História das Ideias Linguísticas", ainda como aponta a mesma autora, não é fazer história da linguística, que poderia ser feita por qualquer historiador, mas trata-se de uma história feita por especialistas da área, capazes de avaliar as diferentes filiações teóricas e suas consequências para a compreensão de ser do próprio objeto, ou seja, a língua. Assim, um dos pontos fulcrais desse tipo de pesquisa é pensar a relação Língua/Nação/Estado e o cidadão que essa relação constitui.

De modo a direcionar este estudo, algumas questões foram propostas e serão respondidas, na medida em que melhor entendermos a manifestação desse saber linguístico nesse instrumento tecnológico, que são as gramáticas. Primeiramente, o que se questiona é como o pensamento grego e latino vem sendo transferido através do tempo até se chegar às gramáticas brasileiras. Uma segunda questão é por que as gramáticas tradicionais brasileiras preservam certos pontos das gramáticas greco-latinas e não outros. Por fim, 


\section{Revista InterteXto / ISSN: 1981-0601}

\section{v. 10, n. 2 (2017)}

uma última questão a ser respondida é por que há uma certa preocupação em se acrescentar o estudo da modalidade nas gramáticas mais recentes.

Outro ponto que deve ser levado em consideração para se entender a origem e transferência de um saber metalinguístico é o conceito de gramatização. Sylvain Auroux (1992, p.65) define gramatização como "o processo que conduz a descrever e a instrumentar uma língua na base de duas tecnologias, que são ainda hoje os pilares de nosso saber metalinguístico: a gramática e o dicionário". De acordo com o mesmo autor, a origem do saber metalinguístico pode ser espontânea (como as tradições chinesa, hindu e grega) ou pode resultar de uma transferência tecnológica (como a tradição latina, a gramática hebraica, o estudo dos vernáculos europeus, ameríndios, africanos). Ele fala ainda em endotransferência, quando a gramática é feita por falantes nativos de uma língua, e exotransferência, quando a gramática é feita por falantes não nativos de uma língua.

Como será melhor notado mais adiante, as gramáticas portuguesas e, consequentemente, as brasileiras são um caso de transferência tecnológica das gramáticas latinas, que por sua vez, são, de certa forma, uma transferência das gramáticas gregas.

\subsection{A QUESTÃO DA MODALIDADE:}

Sabe-se que as noções de modo e modalidade são notoriamente vagas e variam muito de acordo com cada autor que as aborda. No entanto, tentar-se-á chegar a um consenso geral com relação a esses dois conceitos.

A exemplo dessa vagueza nas definições de Modalidade, Palmer (1986) comenta que tal noção engloba aspectos tais como a atitude ou opinião do falante, atos de fala, subjetividade, não factividade, não asserção, possibilidade e necessidade. Para Palmer (1986, p. 16), um critério essencial para a modalidade é a subjetividade dos enunciados. Segundo ele, a "modalidade podia ser definida como a gramaticalização das atitudes e opiniões (subjetivas) dos falantes". 


\section{Revista InterteXto / ISSN: 1981-0601}

v. 10, n. 2 (2017)

Assim, conforme Neves (1996, p.166), as modalidades lexicalizam-se de diferentes maneiras, podendo ser expressas na língua por meio de verbos, sejam auxiliar modal ou de significação plena; de advérbios, que podem se associar a um verbo auxiliar modal; de um adjetivo de posição predicativa; de um substantivo e por meio das próprias categorias gramaticais do verbo da proposição (tempo/modo/aspecto).

Como pode-se notar, a concepção de modalidade, muitas vezes, confunde-se ou pode ser associada às noções de modo verbal e/ou força ilocucionária (tipo de frase). Outro linguista interessado no estudo da Modalidade, Ferenc Kiefer (1987), também apresenta uma série de definições para modalidade, podendo ser conceituada como "uma expressão de possibilidade ou necessidade", "uma expressão da atitude do falante" e como "fator determinante do tipo de sentença".

Os primeiros estudos sobre modalidade foram feitos por Aristóteles, na Grécia Antiga, em "Da interpretação" e "Primeiros Analíticos" (cf. DARRAULT, 1976, p.3 apud DALL'AGLIO-HATTNHER, 1995). Segundo Koch (1987), a lógica aristotélica das modalidades preocupava-se com os valores de verdade de uma proposição, sendo conhecidas essas modalidades como aléticas, ontológicas ou aristotélicas. Distinguiam-se quatro tipos de categorias: o impossível que se opõe ao possível e o necessário que se opõe ao contingente, podendo tais proposições ser contrárias, subcontrárias ou contraditórias.

Assim como aconteceu com a literatura, os estudos gramaticais da tradição grega foram resgatados mais adiante pelos romanos, atingindo, consequentemente, todo o ocidente. Conforme Weedwood (2003, p.34), "foi através dos gramáticos romanos da Antiguidade tardia que a doutrina gramatical grega, filtrada pela língua latina, se incorporou à tradição ocidental dominante".

Mas, durante um período da Idade Média, grande parte do pensamento grego ficou esquecido, principalmente pelo fato de ser o latim a língua dominante. Só quando muitos textos gregos foram traduzidos para o latim, é que foi permitida uma retomada do pensamento grego. Como aponta Cervoni (1989, 


\section{Revista InterteXto / ISSN: 1981-0601}

\section{v. 10, n. 2 (2017)}

p.54), "a análise dos enunciados em duas partes constitutivas, modalidade e conteúdo proposicional, não é nova: os gramáticos da Idade Média, que haviam herdado dos gregos através dos latinos, praticavam-na correntemente". É dessa forma que Aristóteles passa a influenciar muitos pensadores desse período. Esse é o caso de São Tomás de Aquino, que, conforme Nef (1976), em De propositionibus modalibus, faz um esboço dos principais modos e a distinção entre modais de re, cujos modos atingem, através do verbo ao qual elas se ligam, o designatum (a res) do nome, sujeito da frase, e de dicto, cujos modos tem por escopo o dictum.

No período Neoclássico, os estudos sobre modalidade são mais uma vez retomados, como, segundo Cervoni, nos estudos de Arnaud e Nicole (La logique ou L'art de penser). O estudo das modalidades passa a ser interesse tanto dos estudiosos das línguas quanto dos lógicos e matemáticos, como Liebniz, Russel e Frege. No entanto, muito do que a lógica da modalidade propõe não se aplica às línguas naturais, pelo caráter confuso e idiossincrático que elas apresentam.

Já no início do século XX, o membro da Escola de Genebra e discípulo de Saussure, Charles Bally, utiliza-se da distinção entre modus e dictum, feita na Idade Média, fazendo com que tais estudos, finalmente, reaparecessem na linguística contemporânea. As modalidades passam a ser interesse nos estudos sobre lógica da linguagem (B. Pottier, R. Martin) e sobre Performatividade (J. L. Austin), e no desenvolvimento da Semiótica Narrativa (A. J. Greimas, J. Fontanille). Ainda nos estudos linguísticos modernos, Blanché (1969 apud DALL'AGLIO-HATTNHER, 1995) acrescentou outros dois tipos de modalidade às modalidades aristotélicas: as modalidades epistêmicas, que dizem respeito ao eixo do conhecimento, e as modalidades deônticas, que dizem respeito ao eixo da conduta.

\subsection{A QUESTÃO DAS GRAMÁTICAS: DA GRÉCIA AO BRASIL}




\section{Revista InterteXto / ISSN: 1981-0601}

\section{v. 10, n. 2 (2017)}

A Grécia Antiga foi berço de muito do conhecimento gramatical (metalinguístico) que se difundiu no ocidente ${ }^{2}$. Como aponta Weedwood (2003), algumas das preocupações linguísticas que permeiam as gramáticas atuais e a linguística contemporânea foram interesse de muitos filósofos gregos. Platão (c. 429-347 a.C.), por exemplo, no "Crátilo", já questionava a arbitrariedade da língua. Ele ainda faz a distinção entre ónoma e rhêma, palavras usuais para "nome" e "palavra", "dito", "frase", mas que assumem os sentidos técnicos de "sujeito" e "predicado". Aristóteles é muito conhecido pela "Arte Poética" e "Arte Retórica", em que explicita várias das questões estilísticas (tropos e figuras de linguagem) das gramáticas e manuais modernos, além de, como já mencionado, se preocupar com o estudo da modalidade, objeto de interesse desse trabalho.

São importantes também os gregos Apolônio Díscolo, que faz um notável tratado de sintaxe da língua grega, e Dionísio Trácio, que faz uma análise da fonética e da morfologia grega. As concepções das partes do discurso e de modo já aparecem nessas gramáticas. Como aponta Neves (2005), em relação às partes do discurso:

Dionísio o Trácio, na sua téchne grammatiké (§ 11), distingue oito partes do discurso, compondo um esquema com o qual o de nossas gramáticas tem bastante semelhança. (...) São estas as partes do discurso registradas, definidas e examinadas separadamente no manual de Dionísio o Trácio: o nome (ónoma), o verbo (rhêma), o particípio (metoché), o artigo (árthron), o pronome (antonymía), a preposição (próthesis), o advérbio (epírrhema) e a conjunção (sýndesmos). (p.157)

E ainda:

Apolônio Díscolo escreveu uma obra, Sobre a divisão das partes do discurso, que não chegou até nós, mas sua doutrina a

\footnotetext{
${ }^{2}$ Vale lembrar que a tradição linguística ocidental (greco-latina) é uma dentre as diversas tradições que existiram. Conforme Weedwood (2003, p.22), "No plano geográfico, é vão tentar ligar todas as tradições linguísticas numa única sequência cronológica, saltando da Índia à China, à Grécia e a Roma, aos povos semíticos e de volta ao ocidente. Cada tradição tem sua própria história e só pode ser explicada à luz de sua própria cultura e de seus modos de pensamento".
} 


\section{Revista InterteXto / ISSN: 1981-0601}

\section{v. 10, n. 2 (2017)}

respeito desse assunto está nos primeiros capítulos do $D a$ sintaxe das partes do discurso, onde essas partes vêm comparadas aos elementos indivisíveis (stoicheîa) e às sílabas, pela regularidade de seu arranjo na formação de unidades maiores $(I, 1) \cdot(p .172)$

Com relação ao tratamento do modo, a mesma autora (2005, p.210-11) aponta uma série de pensadores gregos que tiveram os diferentes tipos de frase por preocupação. Segundo ela, Protágoras "dividiu a composição retórica em imprecação (eucholé), interrogação (erótesis), resposta (apókrisis) e ordem (entolé)". Aristóteles também distingue tipos de elocução (schémata): "a ordem (entolé), o pedido (euché), a narração (diégesis), a ameaça (apeilé), a interrogação (erótesis) e a resposta (apókrisis)".

Como já fora dito anteriormente, os romanos se apropriaram de muito dos conhecimentos dos gregos. Com a gramática não foi diferente. É dessa forma que Prisciano, um exemplo dentre vários, aplica a doutrina sintática de Apolônio para a língua latina.

Assim, essas primeiras gramáticas gregas influenciaram as gramáticas latinas, que por sua vez, influenciaram fortemente as gramáticas das línguas românicas como o português. Consequentemente, a tradição gramatical portuguesa vem influenciar a tradição gramatical brasileira.

Com relação ao Brasil, Guimarães (2001) expõe os principais acontecimentos que motivaram a produção de gramáticas e dicionários no país. Ele subdivide a história do saber linguístico nessa nação em quatro grandes e importantes momentos institucionais: o primeiro, caracterizado por não haver estudos de língua portuguesa no Brasil, o segundo, caracterizado pelo início de estudos de português no país, o terceiro, caracterizado pela fundação dos cursos de Letras, e o quarto e último, caracterizado pela introdução da Linguística no currículo mínimo dos cursos de Letras e pelo surgimento dos programas de pós-graduação em Linguística.

Além dessa periodização feita por Guimarães (2001), é válido lembrar ainda os apontamentos feitos por Orlandi e Guimarães (2001) sobre a formação 


\section{Revista InterteXto / ISSN: 1981-0601}

v. 10, n. 2 (2017)

das primeiras gramáticas brasileiras, a partir do século XIX. Segundo eles, são três os momentos das gramáticas no Brasil. Inicialmente, por haver uma preocupação com a evangelização dos nativos, as gramáticas existentes eram essencialmente voltadas para a língua indígena. Num segundo momento, o que se tem é uma apropriação das gramáticas portuguesas, para que, finalmente, a partir do século XIX, surjam as primeiras gramáticas "genuinamente" brasileiras, preocupadas com o português do Brasil. Os autores demonstram ainda a influência da constituição de um Estado brasileiro no processo de gramatização desse país. De modo a confirmar isso, eles apontam uma série de gramáticos, suas filiações teóricas e suas preocupações com uma gramática do português brasileiro, sustentada pelo argumento do "novo", ou seja, de que o PB era diferente, sob vários aspectos, do PP.

\section{MODALIDADE E MODALIZAÇÃO NAS GRAMÁTICAS BRASILEIRAS}

Por apresentar como interesse a questão da modalidade nas gramáticas nacionais, foram selecionados alguns desses instrumentos que representassem a constituição de uma tecnologia linguística "brasileira", ou pelo menos que se apresentasse no imaginário de gramática "genuinamente brasileira"; ou seja, foram selecionadas gramáticas desenvolvidas a partir do século XIX, quando se proclama a independência do Brasil e passa a existir uma preocupação em diferenciar a gramática do português falado em Portugal do português falado no Brasil.

Vale lembrar que a partir desse período, a produção gramatical brasileira está fortemente vinculada à concepção de "Língua Nacional" e, como aponta Orlandi e Guimarães (2001), elas estão também associadas ao "argumento do novo", de que as gramáticas do Brasil são novas ou diferentes das gramáticas portuguesas.

Assim, foram analisadas treze gramáticas brasileiras, pertencentes ao quarto e último período mencionado por Guimarães (2001), período em que a 


\section{Revista InterteXto / ISSN: 1981-0601}

\section{v. 10, n. 2 (2017)}

Linguística passa a desempenhar um papel importante na produção de um saber metalinguístico da "língua nacional". São elas: "Gramática Normativa da Língua Portuguesa" (1963), de Silveira Bueno, "Gramática Secundária da Língua Portuguesa" (1964), de Said Ali, "Gramática Elementar da Língua Portuguesa" (1965), de Said Ali, "O Idioma Nacional" (1965), de Antenor Nascentes, "Gramática llustrada" (1982), de Hildebrando Afonso de André, "Novíssima Gramática da Língua Portuguesa" (1985), de Domingos Paschoal Cegalla, "Gramática Normativa da Língua Portuguesa" (1986), de Henrique de Rocha Lima, "Nossa Gramática: teoria" (1990), de Luis Antônio Sacconi, , "Gramática de usos do português" (2000), de Maria Helena de Moura Neves, "Gramática Descritiva do Português" (2001), de Mário Perini, a "Gramática Houaiss da Língua Portuguesa" (2008), de José Carlos de Azeredo, a "Gramática do Português Brasileiro" (2010), de Ataliba Castilho e a "Gramática Pedagógica do Português Brasileiro" (2011), de Marcos Bagno.

Além das gramáticas levantadas, tomou-se também como referência as análises feitas por Hoffnagel (1999) a respeito de modalidade e ensino de língua materna, em cujo artigo a autora analisa sete gramáticas normativas, sendo seis delas brasileiras (a saber: "Gramática Fundamental da Língua Portuguesa" (1978), de Gladstone Chaves de Melo, "Gramática da Língua Portuguesa" (1980), de Celso Ferreira da Cunha, "Gramática Metódica da Língua Portuguesa" (1994), de Napoleão Mendes de Almeida, "Moderna Gramática Portuguesa" (1994), de Evanildo Bechara, "Gramática Normativa" (1972), de Henrique de Rocha Lima, "Gramática da Língua Portuguesa" (1995), de Mário Vilela) e uma gramática portuguesa ("Gramática da Língua Portuguesa" (1989), de Maria Helena de Mira Mateus et al).

O que se nota em uma parte dessas gramáticas brasileiras é que elas foram influenciadas, primeiramente, pelas gramáticas portuguesas, que, por sua vez, herdaram muito da tradição greco-latina. Elas, usualmente, subdividem-se em cinco partes principais: Fonologia, Morfologia, Sintaxe, Semântica e Estilística e têm uma preocupação, essencialmente, normativa, de ensinar o 


\section{Revista InterteXto / ISSN: 1981-0601}

\section{v. 10, n. 2 (2017)}

aluno "falar e escrever 'corretamente' a língua nacional". No entanto, as gramáticas mais recentes, a partir da "Gramática de usos do português" de Maria Helena de Moura Neves, publicada em 2000, apresentam uma subdivisão diferente das demais e um caráter mais descritivo que normativo.

Como menciona Hoffnagel (1999, p.53), sobre a questão da modalidade nas gramáticas de língua portuguesa brasileiras e portuguesa estudadas por ela, "a grande maioria nem sequer menciona o termo modalidade. Todas [as gramáticas], porém, usam o termo modo. Isto, em geral, é feito no capítulo sobre verbo e é simplesmente dito que o verbo em português possui três modos: o indicativo, o subjuntivo e o imperativo".

É assim que se constata que, dentre as gramáticas apontadas acima, apenas as cinco últimas, abordaram a modalidade, como expressão da subjetividade do falante, como um dos seus temas. Na "Gramática de usos do português" de Maria Helena de Moura Neves, que é subdividida em quatro partes (Parte I - A formação básica das predicações: o predicado, os argumentos e os satélites, Parte II - A referenciação situacional e textual: as palavras fóricas, Parte III - A quantificação e indefinição, Parte IV - A junção), o tema da modalidade aparece inserida no item "O Verbo" e no item "Os advérbios", em que a autora abre um subitem sobre os verbos e os advérbios modalizadores.

A "Gramática descritiva do português", de Mário A. Perini, é subdividida em quatro partes também: Parte I: Preliminares, Parte II: Sintaxe, Parte III: Semântica e Parte IV: Lexicologia. Perini, que também traz uma concepção de gramática diferenciada, sob influência dos estudos linguísticos, conceitua modo diferentemente da concepção tradicional. Segundo ele, "o modo se definiria semanticamente como caracterizando 'a atitude do falante frente àquilo que está sendo dito' - uma noção próxima, portanto, à de força ilocucionária, vista no capítulo 3".

Em sua "Gramática Houaiss da Língua Portuguesa" (2008), José Carlos de Azeredo subdivide o estudo gramatical da língua em cinco partes: a primeira, 


\section{Revista InterteXto / ISSN: 1981-0601}

\section{v. 10, n. 2 (2017)}

em que constam os itens "Apresentação", "A gramática e seu estudo" e "Gramática no Brasil: subsídios históricos"; a segunda parte é denominada de "Uma forma de conhecimento, de expressão e de comunicação", a terceira é denominada de "Conceitos básicos de descrição gramatical", a quarta parte se ocupa de "Morfologia flexional e sintaxe", a quinta se preocupa com "A estruturação sonora", a sexta é denominada de "O léxico: formação e significação das palavras" e a sétima e última parte é denominada de "A língua e seus usos expressivos". Diferentemente de todas as outras gramáticas, Azeredo localiza o estudo da modalidade no capítulo quarto da segunda parte, intitulado "Linguagem, discurso e texto". É neste capítulo que ele posiciona a Modalização, num subitem, juntamente com outros itens de caráter textual como Referenciação, Predicação, Tópico e Foco, Coesão e coerência textuais. Quanto à Modalização, ele afirma que

(...) diz respeito à expressão das intenções e pontos de vista do enunciador. É por meio da modalização que o enunciador inscreve no enunciado seus julgamentos e opiniões sobre o conteúdo do que diz/escreve, fornecendo ao interlocutor 'pistas' ou instruções de reconhecimento do efeito de sentido que pretende dizer. (2008, p. 91).

Nessa mesma gramática, o tema da modalidade e modalização aparece também em outros capítulos como em "Capítulo Décimo Quarto: O Período Composto", num subitem que trata da "Quantificação, qualificação e orações modais" e no "Capítulo décimo quinto: Articulação Textual dos Tempos e Modos do Verbo", em notas sobre o Modo verbal.

Por sua vez, a "Gramática do Português Brasileiro" (2010), de Ataliba Castilho, assemelha-se à Gramática de Moura Neves (2000), também de base funcionalista. Ela é subdividida em 15 capítulos: "1. O que se entende por língua e gramática", "2. Os sistemas linguísticos", "3. História do Português Brasileiro", "4. Diversidade do Português Brasileiro", "5. A conversação e o texto", "6. Primeira abordagem da sentença", "7. Estrutura funcional da sentença", "8. 


\section{Revista InterteXto / ISSN: 1981-0601}

\section{v. 10, n. 2 (2017)}

Minissentença e sentença simples", "9. Sentença complexa e sua tipologia", "10. O sintagma verbal", "11. O sintagma nominal", "12. O sintagma adjetival", "13. O sintagma adverbial", "14. O sintagma preposicional" e "15. Algumas generalizações sobre o português brasileiro". A questão da modalidade aparece inserida em três subitens: a) nos estudos da sentença, em que o autor vale-se da distinção entre "modus" e "dictum", conceituando o "modus" como "a avaliação que fazemos do dictum" (p. 321), b) no estudo da sentença complexa, nas propriedades semânticas da sentença matriz, em que ele reconhece oração matriz que contem verbos e adjetivos epistêmicos e de modalização deôntica e pragmática, e, por fim, c) no estudo do sintagma adjetival, na semântica dos adjetivos modalizadores, e no estudo do sintagma adverbial, na semântica dos advérbios predicativos.

Já em sua "Gramática Pedagógica do Português Brasileiro" (2011), Marcos Bagno subdivide seu trabalho em cinco partes: "Epistemologia do Português Brasileiro", "História do Português Brasileiro", "Multimídia do Português Brasileiro", "Lexicogramática do Português Brasileiro" e "Didática do Português Brasileiro". A questão da modalização é abordada na "Lexicogramática do Português Brasileiro", ao tratar as categorias semânticas do verbo, descrevendo os Modos verbais e os Verbos modais. No que diz respeito ao modo, Bagno afirma que "o modo está devidamente gramaticalizado em cada um dos paradigmas morfológicos que permitem ao falante expressar sua atitude com relação ao estado de coisas" (p.556). Sobre os verbos modais, Bagno subdivide diferentes campos modais, afirmando que "a modalização exercida por esses verbos se distribui numa escala que vai da maior possibilidade/probabilidade até a maior necessidade/obrigatoriedade, passando pela vontade/desejo" (p. 572), entendidas como modalidades epistêmica, deôntica e volitiva respectivamente. Nota-se que Bagno está mais preocupado em descrever e apontar diferenças entre PB e PP e mostrar os processos de mudança linguística do PB em sua gramática. Neste caso, toda a metalinguagem, advinda dos estudos linguísticos, tem como objetivo o de 


\section{Revista InterteXto / ISSN: 1981-0601}

\section{v. 10, n. 2 (2017)}

descrever e mostrar as mudanças e singularidades da língua portuguesa falada no Brasil.

Como se vê, após se inserir nos currículos mínimos dos cursos de Letras e integrar cursos de pós-graduação, a Linguística conquista cada vez mais prestígio e autoridade, frente ao seu caráter científico. Conforme Orlandi e Guimarães (2001, p.36), "a questão da língua não é mais da competência do gramático, ela torna-se uma questão dos linguistas. Desde então, a Linguística intervém na produção das gramáticas do português no Brasil (...)". Assim, não só a produção de tecnologias sobre saberes metalinguísticos, neste caso a produção de gramáticas nacionais, passa a ser influenciada pela Linguística, como também os objetivos desses instrumentos tecnológicos mudam.

Maria Helena de Moura Neves, na Apresentação de sua "Gramática de usos do português", afirma:

A Gramática de usos do português parte das tradicionais classes de palavras, ponto de partida escolhido apenas porque o leitor ou consulente comum, sem ser conhecedor do assunto, vai poder situar-se na sua busca, para chegar ao que se quer saber. Entretanto, o agrupamento dessas classes pelas quatro grandes partes da obra já revela que há princípios teóricos dirigindo o tratamento das questões. (p.13) (grifo nosso).

Mais adiante, ao apontar os objetivos de sua gramática, a autora afirma:

A Gramática de usos do português tem como objetivo de prover uma descrição do uso efetivo dos itens da língua, compondo uma gramática referencial do português. É um produto prático, mas de orientação teórica definida, que visa permitir a recuperação da investigação não apenas como conjunto de análises, mas também como conjunto de proposições. (p.14) (grifo nosso).

Já Perini, em seu prefácio, traz as seguintes advertências:

Sustento a ideia de que é responsabilidade dos linguistas brasileiros elaborar uma descrição ampla e detalhada da realidade linguística no Brasil. Entendo essa descrição como abrangendo não só a estrutura da língua padrão (objeto da minha Gramática), mas ainda a descrição da língua coloquial, sua variação social e geográfica, sua história etc. (p.14). 


\section{Revista InterteXto / ISSN: 1981-0601}

\section{v. 10, n. 2 (2017)}

Mais adiante salienta os objetivos de sua gramática:

Meu objetivo é contribuir para uma reorientação radical dos estudos da língua portuguesa: do exame das gramáticas para o exame dos fatos da língua - sem desprezar o exame das gramáticas, mas submetendo-as a uma crítica rigorosa. (...) Este livro pretende ser um exemplo de como se pode fazer uma gramática portuguesa sobre bases teoricamente coerentes, ao mesmo tempo isolando as preocupações normativas (que, por si, não são necessariamente condenáveis) da descrição propriamente dita. (p.15).

Com relação ao público alvo de sua gramática diz:

Ao preparar o texto, pareceu-me indicado dirigir-me, em um primeiro momento, aos profissionais da área: professores de primeiro e segundo graus, alunos e professores dos cursos de Letras. Como se verá, há muita novidade a ser apreendida, assimilada e - principalmente - discutida; só depois será possível pensar em sua aplicação ao ensino de primeiro e segundo graus. (p.16).

O mesmo acontece com a "Gramática Houaiss da língua portuguesa", de Azeredo, em que o autor aponta como objetivos de sua gramática a descrição do uso da língua, a partir de um viés teórico. Para o autor:

Nosso objetivo vai um pouco além da aferição de um uso e sua descrição, enfatizando sempre o dom da palavra como traço singular da espécie humana, empenhamo-nos em refletir sobre o funcionamento da linguagem verbal no seu tríplice papel (a) de forma de organização do conhecimento (conceptualização e categorização da experiência do mundo), (b) de meio de codificação do conhecimento em enunciados/textos (expressão) e (c) de forma de atuação interpessoal (comunicação). (p.25).

Vale notar a influência do pesquisador inglês Michael Halliday, que subdivide o estudo da língua em três macrofunções (ideacional, textual e interpessoal), em sua orientação teórica gramatical. Diferentemente das outras gramáticas, Azeredo (2009) dá um grande enfoque para os aspectos textuais da língua, algo que outras gramáticas o fazem de maneira não muito enfática. Talvez, por conta disso, a modalidade/modalização é tratada como um item que merece destaque a parte, algo que aparece nas outras gramáticas como um 


\section{Revista InterteXto / ISSN: 1981-0601}

\section{v. 10, n. 2 (2017)}

fenômeno semântico relacionado ao estudo da sentença, do verbo, do adjetivo e do advérbio.

Também Castilho (2010) salienta a importância das pesquisas linguísticas que orientaram a elaboração de sua gramática. Como ele mesmo diz, "deixando de lado uma bisonha repulsa aos achados da Gramatica tradicional, este livro mostra como as pesquisas linguísticas, na verdade, aprofundaram e enriqueceram esses achados, operando a partir de princípios e aplicando uma metodologia segura" (2010, p.33). Fica claro também que o autor segue uma orientação teórica de descrição gramatical da língua de base funcionalista.

O caráter de descrição científica da língua também aparece na "Gramática Pedagógica do Português Brasileiro". Logo de início, Bagno afirma que seu trabalho "é uma gramática na medida em que pretende examinar e descrever o funcionamento de uma língua específica" (p. 13). Sua obra se difere de todas as outras por vários aspectos, dentre eles, pelo fato de o autor sinalizar logo no início que sua gramática é "teórica", "político-ideológica" (que entende a gramatização como um tipo de "militância"), "histórica" (pois salienta os aspectos de variação e mudança da língua portuguesa falada no Brasil) e "pedagógica" (por ser pensada em colaborar com a formação docente). Uma das grandes preocupações em sua gramática é mostrar como a língua portuguesa falada no Brasil apresenta aspectos estruturais que a diferem da língua de Portugal. Talvez, por conta disso, a modalidade é vista no interior de fenômenos sintáticosemânticos e não como um fenômeno inerente ao texto, como fez Azeredo.

Enfim, o aparecimento da modalidade nas gramáticas brasileiras pode ser entendido da seguinte forma: primeiramente, o que se tem são gramáticas nacionais influenciadas pela tradição portuguesa, que por sua vez são influenciadas pela tradição greco-latina, e gramáticas nacionais influenciadas por uma nova tradição: linguística. O aparecimento da Linguística no Brasil, a partir da década de 60, passa a desempenhar o papel de marco não só na institucionalização de estudos da língua no Brasil, mas também na produção de aparatos tecnológicos, como gramáticas e dicionários. Nesse sentido, a ciência 


\section{Revista InterteXto / ISSN: 1981-0601}

\section{v. 10, n. 2 (2017)}

tem um papel importante no Estado moderno, sendo de grande interesse para a Nação brasileira, a incorporação da Linguística, como ciência produtora de saber e tecnologia para o bem-estar da sociedade nacional. É por isso que os estudos de modalidade passam a ser foco de interesse nessas gramáticas mais recentes, haja vista sua importância no estudo do uso da língua nacional e no aprimoramento da competência comunicativa do falante da língua portuguesa no Brasil.

\section{CONCLUSÃO:}

Conforme as diferentes sociedades humanas estabeleciam contato entre si, desenvolviam seu comércio e aumentavam sua necessidade de comunicação, saberes sobre as línguas eram produzidos, fossem eles apenas de cunho especulativo ou prático, fossem eles de cunho abstrato e metalinguístico. Algumas dessas diferentes civilizações foram capazes de criar códigos escritos, o que permitiu o desenvolvimento de novas tecnologias de linguagem: as gramáticas e os dicionários. Nesse contexto de origem dos diferentes saberes metalinguísticos é que a modalização passa a ser um saber linguístico de interesse por certos pensadores gregos. Num processo de transferência tecnológica, é retomado pela civilização latina e, posteriormente, por monges e filósofos da Idade Média, para, com o passar do tempo, tornar-se interesse da Linguística contemporânea.

Já o aparecimento das primeiras gramáticas no Brasil se deu em decorrência do contato entre o europeu e os nativos do "Novo Mundo", sob o intuito de evangelização. No entanto, só a partir do século XIX, com a "independência" da colônia portuguesa é que surgem as primeiras gramáticas nacionais, preocupadas com o português falado no Brasil. Com a introdução da Linguística, no currículo mínimo dos cursos de Letras, a partir da década de 1960, um novo período de estudos da língua nacional se instaura. Influenciadas por essa ciência, algumas gramáticas brasileiras passaram, mais recentemente, a ter um caráter mais descritivo que normativo da língua portuguesa, 


\section{Revista InterteXto / ISSN: 1981-0601}

\section{v. 10, n. 2 (2017)}

preocupadas com o "uso" da língua pelos falantes nativos e com o aprimoramento da competência linguística desses "usuários" da língua nacional. Até então, o que se podia verificar nas gramáticas produzidas no Brasil era o emprego do termo "Modo" na descrição dos verbos do português (indicativo, subjuntivo e imperativo). Mas, produzidas por novas autoridades do estudo da língua, os linguistas, algumas gramáticas nacionais recentes, como a "Gramática de usos do português" de Maria Helena de Moura Neves, a "Gramática descritiva do português", de Mário Perini, a "Gramática Houaiss da Língua Portuguesa" (2008), de José Carlos de Azeredo, a "Gramática do Português Brasileiro" (2010), de Ataliba Castilho e a "Gramática Pedagógica do Português Brasileiro" (2011), de Marcos Bagno, retomam os estudos da modalização, que se preocupam com as marcas de subjetividade, ou das atitudes dos falantes, no enunciado.

\section{REFERÊNCIAS BIBLIOGRÁFICAS:}

AUROUX, S. A revolução tecnológica da gramatização. Tradução: Eni Puccineli Orlandi. Campinas: Editora da UNICAMP, 1992.

CASIMIRO, S. Um estudo das modalidades volitiva e deôntica nos discursos do presidente Lula. Dissertação (mestrado). São José do Rio Preto: UNESP Universidade Estadual Paulista, 2007.

CERVONI, J. As Modalidades In: A enunciação. São Paulo Ática, 1989.

DALL'AGLIO-HATTNHER, M. M. A manifestação da modalidade epistêmica: um exercício de análise nos discursos do ex-presidente Collor. Tese (doutorado). Araraquara: UNESP - Universidade Estadual Paulista, Faculdade de Ciências e Letras, 1995.

FIORIN, J. L. Modalização: da língua ao discurso. In: Revista ALFA, São Paulo, 44: 171-192, 2000.

GUIMARÃES, E. Acontecimentos Institucionais e Estudos do Português. In: História da Semântica. Campinas: Pontes, 2001 


\section{Revista InterteXto / ISSN: 1981-0601}

v. 10, n. 2 (2017)

HOFFNAGEL, J.C. A modalidade e seu tratamento no ensino da língua. In: Revista do GELNE, ano 1, nº 1, 1999.

KALINOWISKI, G. Un aperçu elementaire des modalités déontiques. Langages, v.43, p.28-38, 1976.

KIEFER, F. On defining Modality. Folia Linguistica, v. 21, n. 1, p. 67-93, 1987.

LEITE, N. Sobre a Lógica da Estrutura e a questão do Real. In: Psicanálise e Análise do Discurso: O Acontecimento na Estrutura. Rio de Janeiro: Campo Matêmico, 1994.

NEVES, M. H. M. A modalidade. In: KOCH, I. G. V. Gramática do Português Falado. v. 6. Campinas: Editora da Unicamp/Fapesp, 1996, p.163-99.

Unesp, 2002.

A gramática: história, teoria e análise, ensino. São Paulo: Editora

. A vertente grega da Gramática Tradicional: uma visão do pensamento grego sobre a linguagem. São Paulo: Editora Unesp, 2005

NEF, F. De dicto, de re, formule de Barcan et sémantique des mondes possibles. Langages, v.43, p.28-38, 1976.

PALMER, F. R. Mood and modality. New York: Cambridge University Press, 1986

ORLANDI, E. P. Apresentação. In: ORLANDI, E. P. (org.) História das Ideias Linguísticas: construção do saber metalinguístico e constituição da língua nacional. Campinas: Pontes, Cáceres: Unemat, 2001, p. 7-20

ORLANDI, E. P.; GUIMARÃES, E. "Formação de um espaço de produção linguística: a gramática no Brasil”. In: ORLANDI, E. P. (org.) História das Ideias Linguísticas: construção do saber metalinguístico e constituição da língua nacional. Campinas: Pontes, Cáceres: Unemat, 2001, p.21 a 38.

KOCH, I. G. V. As modalidades do discurso. In: Argumentação e linguagem. São Paulo: Cortez, 1987.

WEEDWOOD, B. História concisa da Linguística. São Paulo: Parábola Editorial, 2003.

CÂMARA JR, J. M. História da Linguística. Petrópolis: Vozes, 1975. 
Revista InterteXto / ISSN: 1981-0601

v. 10, n. 2 (2017)

Artigo recebido em 12/07/2017

Artigo aceito em 23/03/2018 